\title{
Longitudinal effects of family and school context on the development on emergent literacy skills in preschoolers
}

\author{
Oriana Incognito ${ }^{1}$ (D) $\cdot$ Giuliana Pinto ${ }^{1}$ (D)
}

Accepted: 27 August 2021

(C) The Author(s) 2021

\begin{abstract}
The negative influence of economic and socio-cultural disadvantages on students' literacy performance has been widely documented. However, the ability of schooling to counterbalance the predictive effect exerted by inequality in the family context has been less investigated. This study aims to longitudinally investigate the relative weight of the child's family context, i.e., parents' occupation and education levels; home literacy; and the school context, in terms of didactical intervention, on emergent literacy skills. A total of 193 children in the last year of preschool participated in the longitudinal research. Each child was administered socio-economic measures (parental education [PE] and home literacy [HL] levels) and, at the beginning and end of the school year, tasks to assess his or her emergent literacy skills (phonological awareness and textual and notational skills). General linear model analyses were carried out. The results of the initial assessment showed that PE level was a powerful predictor of performance that was associated with significantly lower performance in children from disadvantaged backgrounds in all the tested skills. After a year of schooling, all participants benefitted from the teaching received, with significantly increased performance in phonological awareness, notational skills and textual competence. In addition, by comparing the scores of the three groups at the end of the school year, we verified that teaching exerted varying degrees of influence depending on the student group and tested ability.
\end{abstract}

Keywords Home literacy $\cdot$ School literacy $\cdot$ Parents' education level $\cdot$ Phonological awareness $\cdot$ Textual competence $\cdot$ Notational skills

\section{Introduction}

In recent decades, meta-analysis research in the field of developmental psychology has widely documented that a disadvantaged socio-cultural environment has a negative impact on school performance and that this effect is found at all school grades (Domenech \& Krah, 2014; Khanolainen et al., 2020; Van Ewijk \& Sleegers, 2010). Recently, it has been shown that this negative effect exists in preschool (Hartas, 2011). Indeed, it has increasingly been shown that this negative effect occurs in the early grades (D'Angiulli et al., 2004).

There is particularly high interest in studying these effects beginning in the early school years because it has increasingly been found that future academic performance is predicted by

Oriana Incognito

oriana.incognito@unifi.it

1 Department of Education, Languages, Intercultures, Literatures and Psychology, University of Florence, Via di San Salvi, 12, 50135 Florence, Italy previous academic performance (Pinto et al., 2017; Purpura et al., 2011; Suggate et al., 2018).

It is clear that it is important to investigate the impact of socio-economic status (SES) on the early acquisition of school skills precisely because subsequent knowledge is predicted by academic performance in previous grade. One area of particular interest in which the effects on school skills have been studied is literacy because of its relevance both in the short term (instrumental acquisition of reading and writing skills) and in the medium and long term as a vehicle for studying and accessing information throughout life.

In the present longitudinal study, the aim was to investigate whether and to what extent the different components of the SES construct influence emergent literacy and whether and to what extent school experience modifies these effects.

\section{Emergent Literacy}

International studies have been conducted on the acquisition processes of emergent literacy skills, and the strong links between these processes and subsequent literacy has been amply 
demonstrated (e.g., Lonigan et al., 2008; Piasta et al., 2018; Piasta \& Wagner, 2010).

Emergent literacy is defined as the informal acquisition of reading and writing skills that begins in the early years of life and that evolves along a continuum (Clay, 1993); in addition, individuals' emergent literacy is shaped by their cultural contexts (Alves, 2019). Since the pioneering studies of Whitehurst and Lonigan (1998), a line of research has developed that has widely investigated the process of the development of such early skills. Emergent literacy skills include phonological awareness, which is predictive of subsequent reading skills (e.g., Kirby et al., 2003), and print awareness and letter knowledge, which have been identified as precursors of later formalized literacy (Whitehurst \& Lonigan, 2001).

A branch of this line of research has underlined how the impact of emergent literacy skills should be considered, taking into account the specificity of a language in terms of the greater or lesser transparency in the transcription of oral to written language. Specifically, in a transparent language, such as Italian, an adequate model of emergent literacy was developed. The model proposed by Pinto et al. (2009) has provided direction for understanding the acquisition of emergent literacy skills for the Italian language. According to the model, there are three main components: phonological awareness (i.e., the ability to identify units of sounds); textual competence (i.e., the child's ability to go beyond the single meaning unit transmitted by a word to construct a relationship network among words in the text); and conceptual knowledge of the writing system, specifically notational skills (i.e., the ability to translate sounds into appropriate written signs). Cohort studies have verified the predictive ability of emergent literacy skills for subsequent reading and writing learning. Specifically, it has been shown that phonological awareness and notational skills predict literacy skills, such as reading and writing code (Pinto et al., 2016), while textual competence predicts subsequent text writing in later grades (Pinto et al., 2018a).

\section{Socio-Economic Status and Emergent Literacy}

Previous studies have documented the effects of sociocontextual variables in relation to emergent literacy skills. The literature in the field of emergent literacy skills has documented that differences in socio-economic status are related to the different way of measuring it. Thus, with different weights, operationalized as parents' occupation and education level, and the weight of home practices have been identified. Past literature reviews have documented that differences in socio-economic status (SES) that are related to children's emergent literacy skills are ubiquitous (Arnold \& Doctoroff, 2003).

Studies on the weight of parents' occupation have shown that economically disadvantaged children acquire language skills more slowly, exhibit delayed letter recognition and phonological sensitivity and are at risk for reading difficulties (Whitehurst \& Lonigan, 1998). Regarding the development of emergent skills Bowman et al. (2001) verified that young children from poor families entered kindergarten with lower literacy levels than their peers. A recent study by Mozzanica et al. (2016) has investigated the association between families' SES (both education and occupation level) and narrative abilities of a large group of Italian typically developing children. The results show a significant relationship between family SES and children's narrative performance. In particular, educational level and working status of both parents are associated with children's narrative performance, but only when considered alone and not in combination. When considering all factors together, only the fathers' educational level and working status appear to be associated with the children's narrative performance.

However, recent research has indicated that income variables have less of an effect than was previously thought, while parents' educational attainment has been given increasing weight (Curenton \& Justice, 2008). Some studies have been conducted to test the predictive ability of different family educational variables. For example, Storch Bracken and Fischel (2008) showed that parental education played a role in predicting children's early literacy skills. Specifically, it was a significant predictor of children's receptive vocabulary, story and print concepts, and general emergent literacy skills. In addition, Curenton and Justice (2008), investigating the influence of maternal education on pre-literacy skills (i.e., understanding of general print conventions, ability to understand the meaning and functionality of printed material, and knowledge of the alphabet) in a sample of at-risk children from disadvantaged backgrounds, showed that children whose mothers had a high education level scored higher for two out of three of the studied emergent skills than children of mothers with a low education level. The effect size for these contrasts was large. This finding indicated that higher maternal education was found to be a salient protective mechanism in pre-literacy development among this sample.

\section{Home Literacy Environment}

Among the SES variables with the greatest impact on literacy are the literacy practices and literacy routines to which the child is exposed from the earliest years of life (De Jong \& Leseman, 2001). The home literacy environment offers the child an opportunity to become familiar with literacy, described as a social practice and form of cultural transmission (Barza \& von Suchodoletz, 2016). The home literacy environment has usually been measured in terms of the availability of reading and writing materials in the home (e.g., number of children's and adult books and magazines, availability of writing materials) and literacy activities (e.g., frequency of parental book reading to children, trips to the library, children's and 
parental exposure to book titles, writing activities with the children) (Korat et al., 2007). Past research has documented the effects of the home literacy environment on children's early literacy skills in several domains, including oral language, letter knowledge, reading ability, and comprehension (e.g., Storch \& Whitehurst, 2001; van Steensel, 2006). In a recent study, Riser et al. (2020) showed that when the family's socio-economic status, the mother's education and the child's cognitive characteristics were controlled, the home literacy environment was significantly associated with both reading and math skills. Specifically, shared book reading emerged as a significant predictor of subsequent reading skills.

\section{School Literacy Context}

In our opinion, a promising research perspective is the perspective that aims to capture complex patterns by investigation the interaction between the various contexts (family, school) in which the student moves rather than examining the linear and direct influence of various components of SES on performance.

An interesting research perspective investigates the school's ability to address and overcome family economic disadvantages. Bronfenbrenner's pioneering studies showed that the home literacy and school environments are not independent. The child brings home literacy experiences from school. It is considered fundamental to study the effects on the development of emerging skills through both the personal experiences (microsystem) and collective school experiences (mesosystem) of the child. Within this framework, several studies have verified that the mixed school environment improves the development of emergent literacy. Recently, studies have shown that low-income children seem to benefit from a school environment where they meet children from other backgrounds (Kahlenberg, 2016; Miller et al., 2017). Other research has highlighted the influence of didactic experiences and school experiences in enhancing children's literacy achievement of preschoolers from low-income environments (Massetti, 2009). School experiences appear to be promising sources of influence to explain the mechanisms through which economic status affects the outcomes of emergent literacy skills (Aikens \& Barbarin, 2008) and emergent numeracy skills (Sepúlveda et al., 2020).

According to national guidelines, Italian curricula include activities targeting the development of graphomotor skills, literacy-related skills, and sensorial skills. Preschool children are generally not exposed to the formal teaching of reading and spelling, which occurs in first grade. Educational activities for kindergarten children are divided into the following five "fields of experience" identified by Ministerial Decree 254 of 2012, which contains the national guidelines for the kindergarten curriculum and the first cycle of education: the self and the other; the body and movement; images, sounds, and colours; speech and words; and knowledge of the world.

\section{Rationale and Aim}

While the study of the direct but isolated effects of socioeconomic and cultural variables on literacy is well established, internationally, there has been less exploration of the Italian school context. To our knowledge, there has been even less longitudinal research on the interaction of different experiences (family and school) and their effect on learning and, more specifically, on emergent literacy. Few studies have shown whether and to what extent the school can counterbalance the negative effect of environmental disadvantage. It is important to verify whether school literacy matters and how it relates to other variables. The results found in other school systems and on different language systems cannot be automatically transposed or generalized. The school system in Italy, according to the Italian Constitution, aims to offer the same opportunities to all children and to overcome socio-economic differences. The overall purpose of this study was to deepen the understanding of the relationship between the emergent literacy skills of preschool children and the contextual factors related to the development of skills, specifically children's socio-economic status and the learning resources made available to them by the school. In addition, our study aimed to provide information about the possibilities and limits of schools in their interaction with family literacy practices.

We chose to conduct our own survey of 5-year-old preschoolers, which allowed us to collect important information on a crucial period of schooling. The last year of kindergarten is, in fact, the year that precedes the transition to formalized schooling; thus, the mastery of the prerequisites for formalized learning is extremely important.

In detail, we investigated whether the socio-economic context and home literacy influence emergent literacy skills in the Italian sample, whether schooling has an influence on emergent literacy skills and whether emergent literacy skills vary across SES groups. Finally, we verified the power of home literacy to influence competences through their interaction with SES variables.

Specifically, we hypothesized that (a) at the beginning of the school year, children from disadvantaged backgrounds would have statistically lower scores than children from socio-economically advantaged backgrounds or those with a medium level of advantage (with advantage assessed based on parents' occupation and parents' education) in emergent literacy (phonological awareness, textual competence, and notational skills); (b) after receiving specific instructions for a year in the school environment, children's performance in the initially measured emergent literacy skills would increase; and (c) the school experience would affect emergent literacy skills differently depending on the SES group, and home literacy 
would moderate the effects of the socio-economic variable on emergent literacy outcomes.

\section{Method}

\section{Participants}

A total of 193 children participated in the research (M-age = 4.86; $54 \%$ males and $46 \%$ females). These participants were randomly extracted from a larger cohort of students, who were representative of the population. All participants were attending the last year of kindergarten. The last year of kindergarten represents a moment of transition to primary school for preschoolers. The writing and reading of children at this age are not yet formalized and conventional. In Italy, approximately 96\% of preschools are public, and approximately $98 \%$ of children attend them. School activities are based on a national curriculum established by the Ministry of Education. School hours are approximately $40 \mathrm{~h}$ per week. For each child, both parents provided and signed an informed consent form for their child's participation.

\section{Measures}

\section{Parents' Socio-Economic Variables}

Parents were asked about their jobs and education levels, which were examined separately. From these data, two indices were derived: a socio-economic index of occupational status, following the International Standard Classification of Occupations (ISCO-08, 2008) and the Standard International Socio-Economic Index of Occupational Status (ISEI, Ganzeboom, et al., 1992), and a socio-economic index of educational status, following the International Standard Classification of Education (ISCED 2011). Both were estimated categorical scales with low, medium and high levels.

\section{Home Literacy}

To investigate preschool children's access to literacy materials, we used a questionnaire that was completed separately by the mother and father. The questionnaire required parents to describe their children's writing and reading behaviour. In particular, we wanted to determine the extent of the reading material that children between three and five years old had access to at home; parents' habits with regard to reading with and to the child; parent's opinions on how they approached the child's development of oral language, writing and reading; parents' observations on the child's behaviour with regard to written language; and how parents answered any questions on the subject. The questionnaire collected data on activities consistent with existing models, including activities in which both father and mother are involved (e.g., "When do you read books to your child?" and "Do you try to teach the child the first elements of writing/reading?"). The questionnaire consisted of 15 items. A composite score was generated by averaging the mother's and father's scores. In the data used in this study, the Cronbach's alpha coefficient for the composite measure of the home literacy context was .70.

\section{School Literacy}

The school literacy experience is linked to measures that detect emergent literacy skills. The activities carried out at school are non-directed activities on literacy, such as phonology exercises (nursery rhymes, ditties) and oral narrations. The proposed measures are chosen because they adequately capture the emergent literacy skills that are offered to children in Italian preschool.

\section{Emergent Literacy Measures}

For this research, we took the abovementioned emergent literacy model proposed by the authors in 2009 as the reference model.

\section{Phonological Awareness}

To assess phonological awareness, a task involving the identification and production of sound patterns was administered (Pinto et al., 2009). Children were exposed to two verbal stimuli, one containing rhymes and the other containing a series of alliterating words. Children were asked to listen to a poem and invent a similar poem, with the stimuli acting as examples. Three scores were derived for rhythm (children's ability to reproduce the prosody), rhyme (children's ability to detect the rhymes within the stimulus), and alliteration (children's ability to detect alliterations within the stimulus); a score of 0 indicated no rhythm/rhyme/alliteration produced, 1 indicated one rhythm/rhyme/alliteration produced, and 2 indicated two or more rhythms/rhymes/alliterations produced. The agreement index of independent judges was between $90 \%$ and $99 \%$. The alpha coefficient for this instrument was .82 .

\section{Notational Skills}

Notational skills were evaluated with an invented spelling and reading task (Bigozzi et al., 2016). Children were asked to draw, write, and read as best they could. The task consisted of seven invented writing items and seven invented reading items. The children's invented spelling of words was categorized into four sequential schemes: graphic scheme, pseudowriting, symbolic scheme, and conventional spelling. Each item was coded, and a mean score was calculated. Participants' scores ranged from a minimum of 0 to a 
maximum of 3 . The agreement index of independent judges was between $90 \%$ and $99 \%$. The alpha coefficient for this instrument was .92 .

\section{Textual Competence}

To evaluate children's narrative skills, a story production task was used (Pinto et al., 2009). Children were asked to tell a story. The story was recorded, transcribed, and analysed by two independent judges. The parameter evaluated was the story structure with five levels of complexity according to the presence, absence, and/or combinations of eight fundamental elements: title, conventional story opening, characters, setting, problem, central event, resolution, and conventional story closing. The scores ranged from 0 to 5 . The agreement index of independent judges was between $90 \%$ and $99 \%$. The alpha coefficient for this instrument was .91 .

\section{Research Design}

This study had a longitudinal design. Emergent literacy measures were administered at time 1 (T1) and again after one year of schooling (equal to 9 months; time 2 [T2]) to all participants. At time 1, information on the parental socio-cultural level was also collected, and both parents were given the questionnaire on home literacy practices. Graph 1 shows the procedure used for this study.

\section{Data Analyses and Results}

All participants were divided into three levels (low, medium, high) according to their parents' occupation and education levels and into two levels (low and high) for the home literacy variable.

A total of $13 \%$ of children had parents with low-level occupations, $31 \%$ had parents with medium-level occupations, and $56 \%$ had parents with high-level occupations.
In total, $32 \%$ of children had parents with low education levels, $15 \%$ had parents with medium education levels, and $53 \%$ had parents with high education levels.

In addition, participants were divided into two groups based on home literacy level: $45 \%$ had a low home literacy level, and $51 \%$ had a high level, while $4 \%$ were missing values for this variable.

The descriptive statistics of the sample (mean and standard deviation) and correlational matrix were calculated. The descriptive statistics for phonological awareness, notational skill and textual competence are reported in Table 1.

Correlation matrices with Spearman coefficients are shown in Table 2 for the T1 variables. All variables are correlated, with the exception of parental occupation, which is not discussed further.

To verify the initial relationship (T1) between parents' education level (PE), home literacy (HL) and emergent literacy variables, a GLM analysis was used. Bonferroni's post hoc test was performed to establish the differences between the identified groups. Table 3 shows a summary of the significant differences between the groups at both time 1 and time 2 .

Regarding phonological awareness, at the beginning of the school year, only an effect of parents' education is found ( $p<$ .001 , adj. R-squared $=.22$ ). Specifically, children with parents with higher levels of education have higher scores than children with parents with both medium and low education levels. There is no effect of the home literacy variable.

For notational skills, there are effects of both parents' education $(p<.01)$ and home literacy $(p<.001)$ (adj. R-squared $=.14)$. In particular, children with parents with high education levels have better performance than those with parents with medium and low education levels. With regard to home literacy, children with high home literacy scores have higher scores than those with low HL scores.

With regard to textual competence, there is a direct effect of both parents' education $(p<.01)$ and home literacy practices $(p<.01)$ on the variables at T1 (adj. R-squared $=.08)$. Specifically, children with parents with high education levels score higher than those with

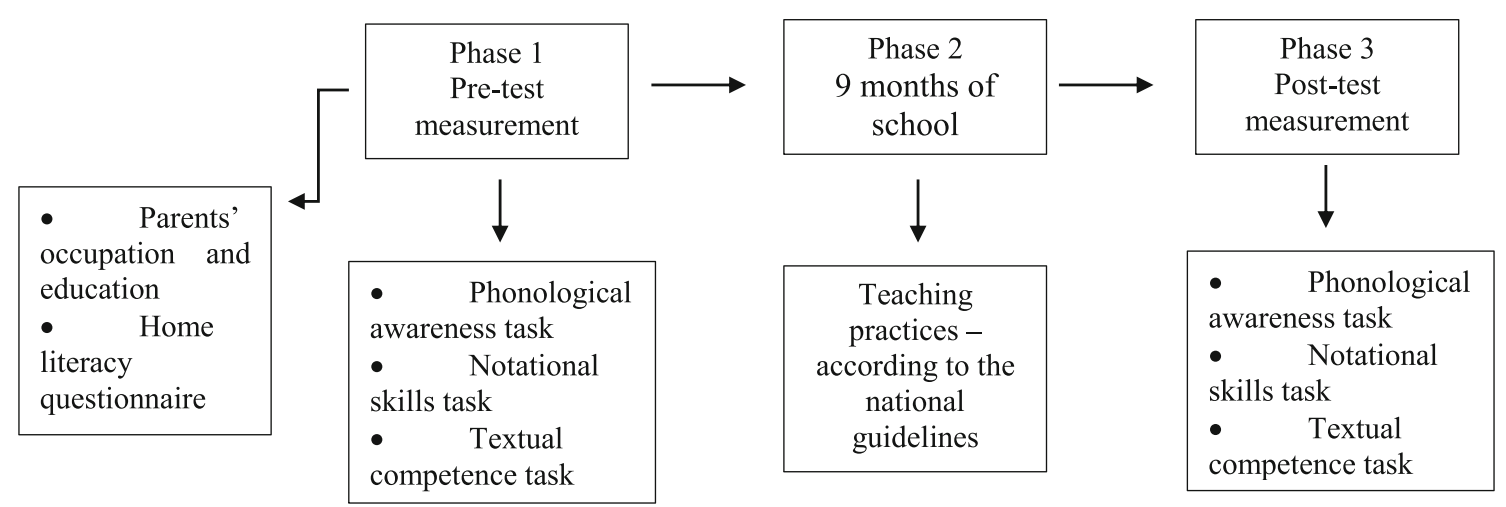

Graph 1 Graphic representation of the research des 
Table 1 Descriptive statistics about the dependent variables (phonological awareness, textual competence and notational skill) at T1 and T2, according to Parental Occupation and Education and Home Literacy: mean, standard deviation

\begin{tabular}{|c|c|c|c|c|c|c|c|c|c|}
\hline & & \multicolumn{3}{|c|}{ Parents' occupation level } & \multicolumn{3}{|c|}{ Parents' education level } & \multicolumn{2}{|c|}{ Home literacy } \\
\hline & & Low & Medium & High & Low & Medium & High & Low & High \\
\hline \multirow[t]{3}{*}{$\mathrm{T} 1$} & Phonological awareness & $.35(.48)$ & $1.07(.74)$ & $1.11(.80)$ & $.61(.58)$ & $.63(.67)$ & $1.33(.77)$ & $.87(.76)$ & $1.11(.79)$ \\
\hline & Notational skills & $1.76(.62)$ & $2.09(.97)$ & $1.90(1.56)$ & $1.75(.78)$ & $1.58(1.01)$ & $2.16(.74)$ & $1.70(.90)$ & $2.14(.72)$ \\
\hline & Textual competence & $1.92(1.22)$ & $2.27(1.23)$ & $2.14(1.56)$ & $1.82(1.28)$ & $1.77(1.10)$ & $2.46(1.53)$ & $1.88(1.41)$ & $2.36(1.39)$ \\
\hline \multirow[t]{3}{*}{$\mathrm{T} 2$} & Phonological awareness & $1.60(.58)$ & $1.96(.27)$ & $1.82(.51)$ & $1.68(.62)$ & $1.81(.56)$ & $1.93(.29)$ & $1.78(.54)$ & $1.86(.43)$ \\
\hline & Notational skills & $2.68(.60)$ & $2.85(.35)$ & $2.41(.76)$ & $2.28(.84)$ & $2.83(.41)$ & $2.67(.55)$ & $2.41(.77)$ & $2.71(.56)$ \\
\hline & Textual competence & $3.31(1.09)$ & $3.93(1.21)$ & $3.07(1.41)$ & $2.77(1.30)$ & $3.11(1.23)$ & $3.78(1.30)$ & $3.00(1.48)$ & $3.66(1.20)$ \\
\hline
\end{tabular}

parents with low education levels. The effect of high home literacy is associated with better performance in narrative skills than when it is low.

In a second step, to verify the effects of education level and home literacy variables on emergent literacy variables at T2, the GLM analysis model was used again, and beyond the direct effect, the model interactions were used to verify the role of home literacy as a moderator.

For phonological awareness, the effect of parents' education level remains $(p<.05$, Adj. R-squared = .05). Specifically, the effects remain significant for high PE vs. low PE. However, there is no longer an effect for medium PE vs. high PE.

For notational skills, at the end of the school year, only the effect of parents' education remains $(p<.001$, Adj. Rsquared $=.29$ ). In this case, children with parents with medium education levels score significantly higher than those with parents with low and high education levels. The direct effect of home literacy disappears, and home literacy does not even act as a moderator.

For textual competence, the effects of parents' education level and home literacy remain the same and in the same directions as at T1. In addition, there is a moderating effect of home literacy on the direct effect of parental education $(p<$ .05 , adj. R-squared $=.43$ ).

Table 2 Correlation matrix at Time 1

\begin{tabular}{lllllll}
\hline & 1 & 2 & 3 & 4 & 5 & 6 \\
\hline SES-PO & - & & & & & \\
SES-PE & $.27 * *$ & - & & & & \\
HL & .44 & .04 & - & & \\
Phonological awareness & -.10 & $.44 * * *$ & .11 & - & & \\
Notational skills & -.01 & $.25 * * *$ & $.20 * *$ & $.25 * * *$ & - & \\
Textual competence & -.04 & $.21 * *$ & $.14 *$ & $.33 * *$ & $.44 * *$ & - \\
\hline Note. $* * * p<.001, * * p$ & $<.01, * p<.05$ & & & &
\end{tabular}

\section{Discussion}

The overall aim of this longitudinal study was to investigate the impact of SES, namely, parental education level; home literacy; and school experiences (school didactical practices) on emergent literacy skills in a sample of Italian preschool children.

First, the present results are in line with the literature indicating a limited impact of only parental occupation on emergent literacy skills, defined as phonological awareness, notational skills and textual competence, as parental occupation was irrelevant in our study. In addition, our results converge with those of previous studies showing that parents' education level is an important influencing factor even before children begin formalized schooling (e.g., Cottone, 2012). In general, as we expected, children who came from a family background with a high level of education showed better literacy skills than their lower SES peers. In accordance with the literature on the specific linguistic and cultural context we studied, our results confirm those reported by Curenton and Justice (2008), among others, who found that mothers' education was an important factor associated with children's emergent literacy skills.

The examination of literacy performance at the beginning of the school year also confirms the role played by domestic

Table 3 Bonferroni post hoc test's significant differences at Time 1 and Time 2

\begin{tabular}{llll}
\hline & & PE level & HL level \\
\hline T1 & Phonological awareness & H $>$ M, L & \\
& Notational skills & H $>$ M, L & H $>$ L \\
& Textual competence & H $>$ L & H $>$ L \\
T2 & Phonological awareness & H $>$ L & \\
& Notational skills & M $>$ H, L & H $>$ L \\
& Textual competence & H $>$ L & \\
\hline
\end{tabular}

Note. H: high level, M: medium level, L: low level. PE: parents' education; HL: home literacy. 
literacy practices, which, is articulated in the different components of literacy we studied. In particular, our findings show that there was a direct influence of domestic practices, particularly on textual and notational skills, while there was a less pronounced influence on phonological skills. For both textual and notational skills, children with high home literacy performed significantly better than children with low home literacy. In line with the questionnaire used, all of the home literacy experiences seem to be aligned with Bruner's routines (1983) and Wood's scaffolding (1976) and fit with what has been defined as home literacy: the experiences in which children interact with their parents in reading and writing situations, the experiences in which children experience them directly, and the experiences in which children observe parental patterns while reading or writing (Sénéchal et al., 2017; Teale $\&$ Sulzby, 1986). As hypothesized, and in accordance with the literature, this result confirms that the socio-cultural environment (rather than the economic environment) and the child's literacy practices constitute a crucial background for subsequent learning, both directly (Roberts et al., 2005) and indirectly (Mendive et al., 2017).

Another aim of this study was to verify the role played by school literacy. The comparison of the results on emergent literacy skills obtained in the second survey after one year of school allowed us to better understand the role played by school experiences (school literacy). We were interested in determining whether the negative effects of socio-cultural disadvantage remained or whether the opportunities offered by everyday life in the classroom had been able to close the gap created due to the different levels of SES of the families to which they belong. The longitudinal design of the research allowed us to determine that the effect of schooling produced a significant increase in literacy skills in all groups.

First, one year of schooling improved emergent literacy skills measured in all SES groups. These results, which show the importance and complexity of the interaction of school and family contextual effects, highlights the concept of the Vygotskian zone of proximal development. Defined as "the distance between the actual developmental level as determined by independent problem solving and the level of potential development as determined through problem-solving under adult guidance, or in collaboration with more capable peers" (Vygotsky, 1978, p. 86), the zone of proximal development maintains its importance even when the child is in transition to formalized learning. Indeed, the zone of proximal development is not produced only in the school context but in all the relationships that the child establishes in both formal and informal contexts. The child's alphabetic system is stimulated and developed from the daily context in which he/she lives that is pervaded by the written code. Thus, he/she has the opportunity to see writing used by figures significant to him/ her (for example, parents, older siblings) in addition to the teacher who makes explicit to him/her the rules necessary to learn to write.

However, the extent of the advantage differs for the various SES groups and for the various emergent literacy skills studied. First, the effect of schooling balances the weight of HL as an equalizing factor. In other words, the effect of schooling counteracts the effect of domestic literacy skills on emergent literacy skills performance.

The comparison between the groups at the end of the school year shows that the performance of phonological awareness and notational and textual skills of the most disadvantaged PE group remained lower than that of the medium and high PE groups. In other words, schooling failed to close the performance gap introduced by the level of parental education in the most disadvantaged group, which continued to have lower performance than the other two groups.

An interesting result is that schooling improved the performance of the group with a medium level of advantage which showed the same results as the most socially advantaged group for two out of three of the studied skills (phonology and notation). In contrast, schooling failed to balance the outcomes obtained by the three groups in textual skills. Schooling can act on emergent literacy skills such as phonological and notational skills, while deeper skills, such as textual skills, remain predominantly related to family experiences. Although phonological and notational skills are more related to perceptual-motor and executive skills, according to previous studies, they are the most important in terms of predictivity of formalized learning (Kirby et al., 2003; Pinto et al., 2016; Ouellette and Sénéchal, 2017). These results suggest that domestic and school literacy practices do not act in isolation but in close interaction and function differently according to the socio-cultural characteristics and literacy skills of the students.

The greater susceptibility of phonological and notation skills to school stimulation compared to that of textual ability can be understood by considering the different levels of complexity of these skills.

Phonological awareness allows one to attend to, discriminate, remember, and manipulate sounds at the syllabic and phonemic level; it is an ability that is expressed exclusively based on the sound quality of words and does not presuppose any particular cognitive or affective-social skills. Phonological awareness can easily be improved through the repeated exercises such as linguistic games and activities that stimulate the sense of rhythm and the perception of sound differences. Opportunities to play with peers; the sounds of language; and teachers' efforts to permeate school life of children with rhymes, alliterations, rhythmic songs, etc. make the school environment particularly rich in affordances for phonological awareness.

Similarly, notation competence, defined as an understanding of how representations refer to meanings, is particularly 
promoted in school activities. Schools offer a framework that allows children to perform systematic comparisons between different notational tasks and thereby to develop a more coherent picture of various notational abilities. It is plausible that children's learning of different notational systems with features based on cultural conventions is particularly favoured by an environment such as the school environment, which is permeated with codes and opportunities to practice them. In addition, a child who has to learn notational systems by imitation constantly finds models to imitate in his or her more competent peers and teachers.

Phonological awareness and notational skills are the most important for learning. Reducing disadvantage is a protective factor against failure in formalized learning.

In contrast, the finding of the lowest effect on textual skills suggests that these skills are rooted in a very wide and deep network of experiences and linguistic and communicative exchanges. Knowing how to compose a text requires many complex linguistic, cognitive, social and affective skills, such as understanding and planning the intentions and actions of the characters in a story, establishing correct relationships and coherence between the parts of the text, and inferring and building on the underlying causal relationships both within and across story episodes in narrative contexts. Much research in the area of children's narratives has documented that children's narrative capabilities develop in the early childhood years and are well supported by familial practices before school entry. A major source of support for preschool children's narratives comes in the form of adult-child reminiscent conversations, which is typical of family communication, and in the use of mediating resources (for example, conversation partners, objects, and environments that mediate storying) wide-ranging and deliberate.

It is likely necessary to no longer think of the appropriate environment for emergent literacy as a specific set of favourable circumstances that is produced mainly in the school context but rather to think of this environment as a cross-context condition that results from the varied opportunities that a child experiences between school and family. The ability to internalize the instructions coming from social interactions with a competent partner must not be limited to the school hours. According to the bioecological framework by Bronfenbrenner \& Morris (2006), both person characteristics (e.g., child literacy interest) and context variables (e.g., literacy experiences at home and school) are expected to contribute to children's emergent literacy skills. For a student to be provided with the appropriate assistance that gives him or her enough of a "boost" to achieve a task, a dialogue is needed among educators to support the student as he or she is led through the ZPD.
A second reason for the school's inability to ensure that the disadvantage of unequal family support conditions is overcome can be traced back to the quality of literacy teaching. Too often, literacy teaching is only effective for those students who already have a good starting point, an adequate knowledge base and enjoy family support.

\section{Implications}

One implication of the study findings is an indication of the need to invest in the promotion of dialogue between schools and families. From this perspective, an interesting proposal explaining the influence of the family context also highlighted how parents' interest and participation in their children's school life can influence learning. Parents' reports on school involvement represent the interaction of two contexts - family and school (Pastorelli et al., 2019). In this case, parents' interest and responsibility in the school environment could promote or hinder children's dedication to learning offered at school.

A second implication is a suggestion for the requalification of the teaching methods by which teachers guide novice students in familiarizing themselves with the various skills that make up emergent literacy. Several empirical studies have provided empirical evidence of the possibility of adopting effective teaching practices in promoting the various aspects of literacy, such as phonological awareness (Blachman et al. 1999; Soto et al. 2019), notational awareness (Pinto et al., 2018b; Rieben et al., 2009), and textual awareness (Nicolopoulou, 2019; Pinto et al., 2019), for which we documented little improvements in children with social and cultural disadvantages. In this direction, teachers should receive the latest psychological and pedagogical knowledge on the most promising teaching practices.

\section{Limitations}

As suggested by other studies (Curenton \& Justice, 2008), it would be appropriate to consider paternal and maternal SES (both occupation and educational level) separately.

The home literacy questionnaire used in this study does not consider tools from the digital world (e.g., ebooks, digital tablets). Indeed, literacy skills emerge through socio-cultural interactions with both non-digital tools and digital tools (Neumann et al., 2017). $t$ would be desirable for future research to consider the assessment of home literacy by developing items that take digital literacy into account.

Finally, additional variables should be considered. For example, recent literature also increasingly focuses 
attention on experiences before the preschool level that have been associated with better scores on language and cognitive tests at later times. Specifically, it would be useful to consider whether children received centerbased care in early childhood, as it has been shown to play a protective role in the first 3 years of life (Bulgarelli \& Molina, 2016).

Funding Open access funding provided by Università degli Studi di Firenze within the CRUI-CARE Agreement.

Data Availability not available.

\section{Declarations}

Ethical Statement All the parents of participants gave their informed consent. The study complies with the 1964 Declaration of Helsinki and its later addenda, and the survey on which our study is based was approved by the Ethical Review Board of the Psychology Department, University of Florence, Italy.

With this letter I declare that this original contribution has never been published before, nor has been sent to any other journals for consideration.

I confirm that all co-authors have reviewed and approved the final version of the manuscript that I am submitting and have agreed to the listing-order for authors. The corresponding author is affirming these details on behalf of all authors.

Conflict of interest We have no known conflict of interest to disclose.

Open Access This article is licensed under a Creative Commons Attribution 4.0 International License, which permits use, sharing, adaptation, distribution and reproduction in any medium or format, as long as you give appropriate credit to the original author(s) and the source, provide a link to the Creative Commons licence, and indicate if changes were made. The images or other third party material in this article are included in the article's Creative Commons licence, unless indicated otherwise in a credit line to the material. If material is not included in the article's Creative Commons licence and your intended use is not permitted by statutory regulation or exceeds the permitted use, you will need to obtain permission directly from the copyright holder. To view a copy of this licence, visit http://creativecommons.org/licenses/by/4.0/.

\section{References}

Aikens, N. L., \& Barbarin, O. (2008). Socioeconomic differences in reading trajectories: The contribution of family, neighborhood, and school contexts. Journal of Educational Psychology, 100(2), 235251. https://doi.org/10.1037/0022-0663.100.2.235

Alves, R. A. (2019). The early steps in becoming a writer: Enabling participation in a literate world. In J. S. Horst \& J. von Koss Torkildsen (Eds.), International handbook of language acquisition (pp. 567-590). Routledge.

Arnold, D. H., \& Doctoroff, G. L. (2003). The early education of socioeconomically disadvantaged children. Annual Review of Psychology, 54, 517-545. https://doi.org/10.1146/annurev.psych. 54.111301 .145442

Barza, L., \& von Suchodoletz, A. (2016). Home literacy as cultural transmission: Parent preferences for shared Reading in the United Arab
Emirates. Learning, Culture and Social Interaction, 11, 142-152. https://doi.org/10.1016/j.lcsi.2016.08.002

Bigozzi, L., Tarchi, C., Caudek, C., \& Pinto, G. (2016). Predicting Reading and Spelling Disorders: A 4-Year Prospective Cohort Study. Frontiers in Psychology, 7. https://doi.org/10.3389/ fpsyg.2016.00337

Blachman, B. A., Tangel, D. M., Ball, E. W., et al. (1999). Developing phonological awareness and word recognition skills: A two-year intervention with low-income, inner-city children. Reading and Writing, 11, 239-273. https://doi.org/10.1023/A:1008050403932

Bowman, B. T., Donovan, M. S., \& Burns, M. S. (2001). Eager to learn: Educating our preschoolers. [full report and executive summary.]. National Academy Press.

Bronfenbrenner, U., \& Morris, P. A. (2006). The bioecological model of human development. In R. M. Lerner \& H. Stattin (Eds.), Handbook of child psychology: Vol. 1, theoretical models of human development (pp. 793-828). Wiley.

Bruner, J. (1983). Child's talk: Learning to use language. Norton.

Bulgarelli, D., \& Molina, P. (2016). Early childcare, parental education and family origins: Effect on cognitive and linguistic outcomes in childhood. Revista de Cercetare si Interventie Sociala, 52, 5-25.

Clay, M. (1993). An Observation Survey of Early Literacy Achievement. Heiremann: NH.

Cottone, E. A. (2012). Preschoolers' emergent literacy skills: The mediating role of maternal Reading beliefs. Early Education and Development, 23(3), 351-372. https://doi.org/10.1080/10409289. 2010.527581

Curenton, S. M., \& Justice, L. M. (2008). Children's Preliteracy skills: Influence of Mothers' education and beliefs about shared-Reading interactions. Early Education and Development, 19(2), 261-283. https://doi.org/10.1080/10409280801963939

D'Angiulli, A., Siegel, L. S., \& Hertzman, C. (2004). Schooling, socioeconomic context and literacy development. Educational Psychology, 24(6), 867-883. https://doi.org/10.1080/ 0144341042000271746

David, J., Purpura, L. E., Hume, D. M., Sims, C. J., \& Lonigan,. (2011). Early literacy and early numeracy: The value of including early literacy skills in the prediction of numeracy development. Journal of Experimental Child Psychology, 110(4), 647-658. https://doi.org/ 10.1016/j.jecp.2011.07.004.

De Jong, P. F., \& Leseman, P. P. (2001). Lasting effects of home literacy on Reading achievement in school. Journal of School Psychology, 39(5), 389-414. https://doi.org/10.1016/s0022-4405(01)00080-2

Domenech, M., \& Krah, A. (2014). What familial aspects matter? Investigating argumentative competences of learners at the beginning of secondary schooling in the light of family-based resources. Learning, Culture and Social Interaction., 3, 77-87. https://doi.org/ 10.1016/j.lcsi.2013.12.006

Hartas, D. (2011). Families' social backgrounds matter: Socio-economic factors, home learning and young children's language, literacy and social outcomes. British Educational Researcsh Journal, 37(6), 893-914. https://doi.org/10.1080/01411926.2010.506945

Kahlenberg, R. (2016). School integration in practice: Lessons from nine districts. The Century Foundation.

Khanolainen, D., Psyridou, M., Silinskas, G., Lerkkanen, M.-K., Niemi, P., Poikkeus, A.-M., \& Torppa, M. (2020). Longitudinal effects of the home learning environment and parental difficulties on Reading and math development across grades 1-9. Frontiers in Psychology, 11, 577981. https://doi.org/10.3389/fpsyg.2020.577981

Kirby, J. R., Parrila, R. K., \& Pfeiffer, S. L. (2003). Naming speed and phonological awareness as predictors of reading development. Journal of Educational Psychology, 95(3), 453-464. https://doi. org/10.1037/0022-0663.95.3.453

Korat, O., Klein, P., \& Segal-Drori, O. (2007). Maternal mediation in book reading, home literacy environment, and children's emergent 
literacy: A comparison between two social groups. Reading and Writing, 20, 361-398. https://doi.org/10.1007/s11145-006-9034-x

Lonigan, C. J., Schatschneider, C., Westberg, L., \& The National Early Literacy Panel (2008). Identification of children's skills and abilities linked to later outcomes in reading, writing, and spelling. In National Early Literacy Panel (Ed.). Developing early literacy: A scientific synthesis of early literacy development and implications for intervention (pp. 55-105). National Institute for Literacy \& The Partnership for Reading.

Massetti, G. M. (2009). Enhancing emergent literacy skills of preschoolers from low-income environments through a classroombased approach. School Psychology Review, 38, 554-569.

Mendive, S., Lissi, M. R., Bakeman, R., \& Reyes, A. (2017). Beyond mother education: Maternal practices as predictors of early literacy development in Chilean children from low-SES households. Early Education and Development, 28(2), 167-181. https://doi.org/10. 1080/10409289.2016.1197014

Miller, P., Votruba-Drzal, E., McQuiggan, M., \& Shaw, A. (2017). Pre-K classroom economic composition and children's early academic development. Journal of Educational Psychology, 109(2), 149-165. https://doi.org/10.1037/edu0000137

Mozzanica, F., Ambrogi, F., Salvadorini, R., Sai, E., Pozzoli, R., Barillari, M. R., Scarponi, L., \& Schindler, A. (2016). The relationship between socioeconomic status and narrative abilities in a Group of Italian Normally Developing Children. Folia Phoniatrica et Logopaedica, 68, 134-140. https://doi.org/10.1159/000452443

Neumann, M. M., Finger, G., \& Neumann, D. L. (2017). A conceptual framework for emergent digital literacy. Early Childhood Education Journal, 45, 471-479. https://doi.org/10.1007/s10643-016-0792-z

Nicolopoulou, A. (2019). Using a storytelling/story-acting practice to promote narrative and other decontextualized language skills in disadvantaged children. In E. Veneziano, \& A. Nicolopoulou (Eds.), Narratives, interventions and literacy: Promoting narrative proficiency and other skills (pp. 283-304). John Benjamins.

Ouellette, G., \& Sénéchal, M. (2017). Invented spelling in kindergarten as a predictor of reading and spelling in grade 1: A new pathway to literacy, or just the same road, less known? Developmental Psychology, 53, 77-88. https://doi.org/10.1037/dev0000179

Pastorelli C., Bacchini D., Thartori E., Di Giunta L., Miranda M.C. (2019). Education and parenting in Italy. In: Sorbring E., Lansford J. (eds) school systems, parent behavior, and academic achievement. Young people and learning processes in school and everyday life, vol 3. Springer, Cham.

Piasta, S. B., \& Wagner, R. K. (2010). Developing early literacy skills: A Meta-analysis of alphabet learning and instruction. Reading Research Quarterly, 45, 8-38. https://doi.org/10.1598/RRQ.45.1.2

Piasta, S. B., Groom, L. J., Khan, K. S., Skibbe, L. E., \& Bowles, R. P. (2018). Young children's narrative skill: Concurrent and predictive associations with emergent literacy and early word reading skills. Reading and Writing, 31, 1479-1498. https://doi.org/10.1007/ s11145-018-9844-7

Pinto, G., Bigozzi, L., Accorti, B., \& Vezzani, G. C. (2009). Emergent literacy and learning to write: A predictive model for italian language. European Journal of Psychology of Education, 24(1), 6178. https://doi.org/10.1007/BF03173475.

Pinto, G., Bigozzi, L., Tarchi, C., Vezzani, C., \& Accorti Gamannossi, B. (2016). Predicting Reading, Spelling, and Mathematical Skills: A Longitudinal Study From Kindergarten Through First Grade. Psychological Reports, 118(2), 413-440. https://doi.org/10.1177/ 0033294116633357.

Pinto, G., Bigozzi, L., Vezzani , C., \& Tarchi, C. (2017). Emergent literacy and reading acquisition: a longitudinal study from kindergarten to primary school. European Journal of Psychology of
Education, 32(4), 571-587. https://doi.org/10.1007/s10212-0160314-9.

Pinto, G., Bigozzi, L., Tarchi, C., \& Camilloni, M. (2018a). Improving Conceptual Knowledge of the Italian Writing System in Kindergarten: A Cluster Randomized Trial. Frontiers in Psychology, 9. https://doi.org/10.3389/fpsyg.2018.01396

Pinto, G., Tarchi , C., \& Accorti Gamannossi, B. (2018b). Kindergarteners' Narrative Competence Across Tasks and Time. The Journal of Genetic Psychology, 179(3), 143-155. https://doi. org/10.1080/00221325.2018.1453775.

Pinto, G., Tarchi, C., \& Bigozzi, L. (2019). Promoting narrative competence in kindergarten: An intervention study. Early Childhood Research Quarterly, 47, 20-29. https://doi.org/10.1016/j.ecresq. 2018.09.003.

Rieben, L., Ntamakiliro, L., Gonthier, B., Fayol, M., \& Fayol, M. (2009). Effects of various early writing practices on reading and spelling effects of various early writing practices on reading and spelling. Scientific Studies of Reading, 9, 145-166. https://doi.org/10.1207/ s1532799xssr0902

Riser, Q. H., Rouse, H. L., Choi, J. Y., \& Ku, S. (2020). The contribution of home literacy context to preschool academic competencies for American Indian and Alaska native children. Child \& Youth Care Forum, 49, 303-323. https://doi.org/10.1007/s10566-019-09529-1

Roberts, J., Jurgens, J., \& Burchinal, M. (2005). The role of home literacy practices in preschool children's language and emergent literacy skills. Journal of Speech, Language, and Hearing Research, 48, 345-359. https://doi.org/10.1044/1092-4388(2005/024)

Sénéchal, M., Whissell, J., \& Bildfell, A. (2017). Starting from home: Home literacy practices that make a difference. In K. Cain, D. Compton, \& R. Parrila (Eds.), theories of reading development (pp. 383-408). Amsterdam, the Netherlands: John Benjamins.

Sepúlveda, F., Rodríguez, C., \& Peake, C. (2020). Differences and associations in symbolic and non-symbolic early numeracy competencies of Chilean kinder grade children, considering socioeconomic status of schools. Early Education and Development, 31(1), 137151. https://doi.org/10.1080/10409289.2019.1609819

Soto, X., Olszewski, A., \& Goldstein, H. (2019). A systematic review of phonological awareness interventions for Latino children in early and primary grades. Journal of Early Intervention, 41(4), 340365. https://doi.org/10.1177/1053815119856067

Storch Bracken, S., \& Fischel, J. E. (2008). Family Reading behavior and early literacy skills in preschool children from low-income backgrounds. Early Education and Development, 19(1), 45-67. https:// doi.org/10.1080/10409280701838835

Storch, S. A., \& Whitehurst, G. J. (2001). The role of family and home in the literacy development of children from low-income backgrounds. New Directions for Child and Adolescent Development, 92, 53-72. https://doi.org/10.1002/cd.15

Suggate, S., Schaughency, E., McAnally, H., \& Reese, E. (2018). From infancy to adolescence: The longitudinal links between vocabulary, early literacy skills, oral narrative, and reading comprehension. Cognitive Development, 47, 82-95. https://doi.org/10.1016/j. cogdev.2018.04.005

Teale, W. H., \& Sulzby, E. (1986). Emergent literacy as a perspective for examining how young children become writers and readers. In W. H. Teale \& E. Sulzby (Eds.), Emergent literacy: Writing and reading (pp. vii-xxv). Ablex.

Van Ewijk, R., \& Sleegers, P. (2010). The effect of peer socioeconomic status on student achievement: A meta-analysis. Educational Research Review, 5, 134-150. https://doi.org/10.1016/j.edurev. 2010.02.001

Van Steensel, R. (2006). Relations between socio-cultural factors, the home literacy environment and children's literacy development in 
the first years of primary education. Journal of Research in Reading, 29, 367-382. https://doi.org/10.1111/j.1467-9817.2006.00301.x

Vygotsky, L. S. (1978). Mind in society: The development of higher psychological processes. Harvard University Press.

Whitehurst, G. J., \& Lonigan, C. J. (1998). Child development and emergent literacy. Child Development, 69, 848-872. https://doi.org/10. 1111/j.1467-8624.1998.tb06247.x

Whitehurst, G. J., \& Lonigan, C. J. (2001). Emergent literacy: Development from pre-readers to readers. In S. B. Neuman \& D.
K. Dickinson (Eds.), Handbook of early literacy research (pp. 1129). Guilford Press.

Wood, D., Bruner, J. S., \& Ross, G. (1976). The role of tutoring in problem solving. Journal of Child Psychology and Psychiatry, 17, 89-100. https://doi.org/10.1111/j.1469-7610.1976.tb00381.x

Publisher's Note Springer Nature remains neutral with regard to jurisdictional claims in published maps and institutional affiliations. 